\title{
Omphalocele with Dextrocardia - A Rare Association
}

\author{
Shakya VC, ${ }^{1}$ Agrawal CS, ${ }^{1}$ Shrestha NR, ${ }^{2}$ Dhungel K, ${ }^{3}$ Adhikary $S^{1}$ \\ 'Department of Surgery, ${ }^{2}$ Department of Medicine, ${ }^{3}$ Department of Radiology, B. P. Koirala Institute of Health Sciences, Dharan, \\ Nepal.
}

\begin{abstract}
Omphalocele is frequently associated with many other congenital malformations. In cardiac anomalies, association of omphalocele with dextrocardia has been rarely noticed before. We present here a child with dextrocardia and omphalocele alongwith a brief review of the literature on this rare association.
\end{abstract}

Key Words: congenital malformations, dextrocardia, omphalocele

\section{INTRODUCTION}

Omphalocele and gastroschisis are the two most common congenital malformations of the anterior abdominal wall. Omphalocele is a midline abdominal wall defect with extrusion of abdominal viscera, covered by a membranous sac, into the base of the umbilical cord. Omphalocele is frequently associated with many other congenital malformations, like cardiac anomalies, ranging at the rate of 15 to $54 \% .^{1-7}$ In cardiac anomalies, association of omphalocele with dextrocardia has been noticed in very few literatures only. ${ }^{3,4}$ We describe here such a rare association, with a brief review of the literature.

\section{CASE REPORT}

A two day old male neonate presented to our surgical unit with an abdominal wall defect (Figure 1). On examination, the child was morphologically normal except for the omphalocele, his vitals were stable, and on examination of the chest the heart sounds were predominantly heard on the right side. A radiograph of the chest and abdomen showed the heart shadow in the right side, along with the omphalocele sac (Figure 2). An echocardiography was done, which showed dextrocardia of the heart, without other anomalies (Figure 3). The omphalocele sac was excised after opening the sac and freeing the contents which were cecum, ascending colon and distal ileum. Anatomical closure of the anterior abdominal wall was done. There were no complications in post-operative period. At three months follow-up, the child was doing well.

\section{DISCUSSION}

Omphalocele is a sporadic abnormality with a birth prevalence of about 1 in 4000 . The sac is composed of peritoneum, amnion and Wharton's jelly. Visceral contents in the sac may include loops of intestine, liver, and stomach. Omphalocele has been found to be isolated or associated with various other malformations, like chromosomal abnormalities, non-chromosomal syndromes (including Beckwith-Wiedemann syndrome, Goltz syndrome, Marshall-Smith syndrome, MeckelGruber syndrome, Oto-palato-digital type II syndrome, CHARGE syndrome, and fetal valproate syndrome) malformations (like ectopia cordis, body stalk anomaly,

Correspondence:

Dr. Vikal Chandra Shakya

Department of Surgery

B. P. Koirala Institute of Health Sciences

Dharan, Nepal.

Email: vikalcsh@yahoo.com

Phone: 977-9842173106 


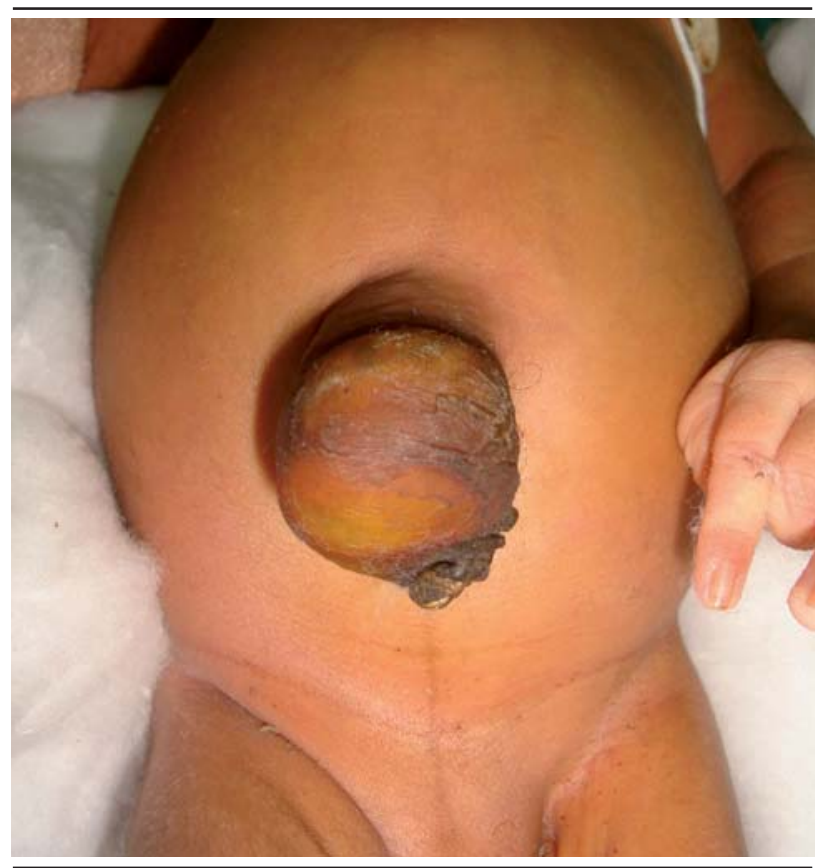

Figure 1. Photograph showing the omphalocele.

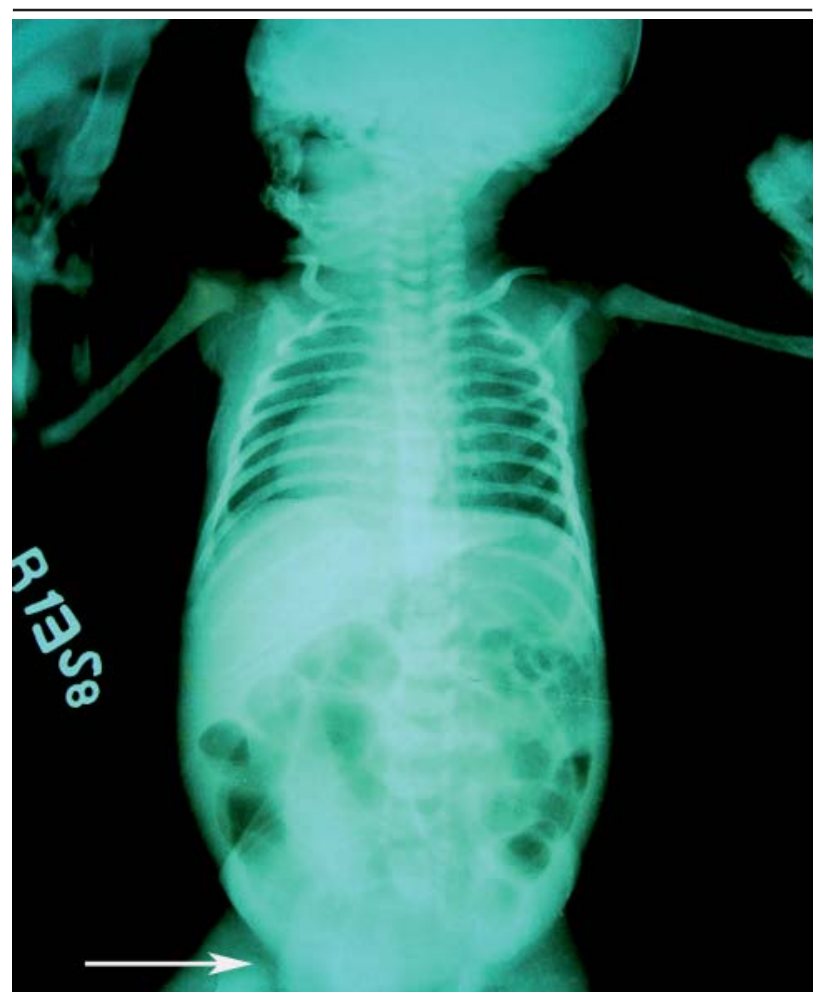

Figure 2. A plain radiograph of the chest and abdomen showing dextrocardia and the omphalocele sac (arrow)

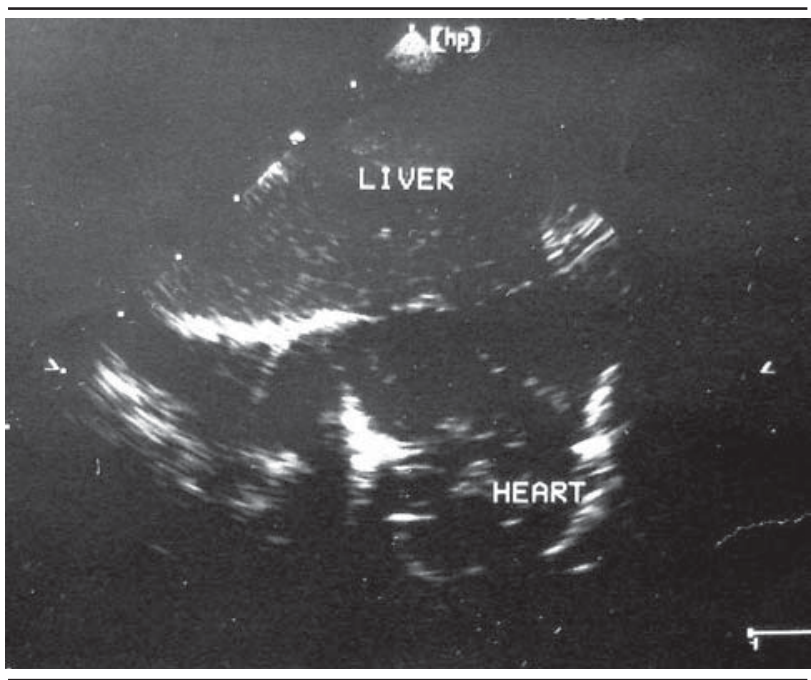

Figure 3. Echocardiography showing dextrocardia (heart positioned above the liver)

exstrophy of bladder, exstrophy of cloaca, and OEIS), malformation complexes (including Pentalogy of Cantrell) and non-syndromic multiple congenital anomalies. ${ }^{1-}$

7 Malformations of the cardiovascular system include one of most common congenital malformations in patients with omphalocele. However, dextrocardia with omphalocele has been reported in very few literatures, even including large series. . $^{3,4}$

In Stoll et al's study, dextrocardia has been found to be associated with 5 out of 68 patients. ${ }^{3}$ Ventricular septal defect was the commonest, dextrocardia was the second commonest. In another study by Mayer et al, two out of 28 patients had associated dextrocardia, alongwith anophthalmia, microcephaly, and trisomy-13; both these child did not survive. ${ }^{4}$ In many other studies, dextrocardia has not been mentioned. ${ }^{5,6}$ Common heart diseases that have been found with it include ventricular septal defect, atrial septal defect, Tetralogy of Fallot, hypoplastic left ventricle and coarctation of aorta. ${ }^{3-7}$

Isolated dextrocardia has not been associated with an increased mortality rate. ${ }^{3,4}$ Dextrocardia in combination with other anomalies (multiple or chromosomal anomalies) definitely has been associated with an increased mortality, and the available literatures show that mortality is mainly attributable to the associated anomalies. $^{3,4}$ Hence, some authors have even considered screening for other congenital malformations as mandatory in patients with omphalocele. ${ }^{3}$ This case report highlights isolated dextrocardia as a possible association with omphalocele. 


\section{REFERENCES}

1. Fisher R, Attah A, Partington A, Dykes E. Impact of antenatal diagnosis on incidence and prognosis in abdominal wall defects. J Pediatr Surg. 1996 Apr;31(4):538-41.

2. Tan KH, Kilby MD, Whittle MJ, Beattie BR, Booth IW, Botting BJ. Congenital anterior abdominal wall defects in England and Wales 1987-93: retrospective analysis of OPCS data. BMJ. 1996 Oct 12;313(7062):903-6.

3. Stoll C, Alembik Y, Dott B, Roth MP. Omphalocele and gastroschisis and associated malformations. Am J Med Genet A. 2008 May 15;146A(10):1280-5.

4. Mayer T, Black R, Matlak ME, Johnson DG. Gastroschisis and omphalocele: an eight- year review. Ann Surg. 1980 Dec;192(6):783-7.
5. Henrich K, Huemmer HP, Reingruber B, Weber PG. Gastroschisis and omphalocele: treatments and long-term outcomes. Pediatr Surg Int. 2008 Feb;24(2):167-73.

1. 6.Tulloh RM, Tansey SP, Parashar K, DeGiovanni JV, Wright JG, Silove ED. Echocardiographic screening in neonates undergoing surgery for selected gastrointestinal malformations. Arch Dis Child Fetal Neonatal Ed. 1994 May;70(3):F206-8.

6. Gibbin C, Touch S, Broth RE, Berghella V. Abdominal wall defects and congenital heart disease. Ultrasound Obstet Gynecol. 2003 Apr;21(4):334-7. 